towards the cost of a survey of the incidence and nature of long-term illnesses in a cross-section of the population of Baltimore, Maryland, and a third for a survey of the Rochester regional hospital programme. The other two were for a study of family experience with medical care in an urban population group and for planning and organizing programmes to improve medical care in selected Tennessee communities.

Of the thirteen grants for medical research, four were new, one of these being a survey of the work of the Child Research Council of the School of Medicine, University of Colorado. Much the largest grants in this group are those for studies of neural correlates of mental activity at the University of California School of Medicine and for the study of personality development at the Child Study Centre, Yale University; but large grants were also made for studies of resistance and susceptibility to experimental tuberculosis (Henry Phipps Institute, University of Pennsylvania School of Medicine), histochemical studies of the sub-microscopic organization of cells and extrecellular substances (Department of Anatomy, University of Chicago), studies of cerebral function (New York University College of Medicine), a twin study of the hereditary and environmental factors in body build (Institute for the Study of Human Variation, Columbia University) and a study of the biological role of steroids (Worcester Foundation for Experimental Biology).

For advanced fellowships in medicine and allied fields, the Fund appropriated 100 million dollars, and the eighteen awerds included eight for interdisciplinary study, five for special work relating to psychiatry, two for training in research and three for special experience and study. In the field of international education the major appropriation in 1953-54 was $685,890,000$ dollars for a two-year budget for the established programme of the Commonwealth Fund fellowships for advanced study and travel in the United States. New awards under the programme, which also provides for the maintenance of Harkness House, London, included twenty general British fellowships, three Home, six Dominion and two Colonial Civil Service fellowships, and three journalism fellowships, while a two-year grant was made to the Institute of International Education and a one-year grant to the Salzburg Seminar in American Studies.

\section{BLOOD COAGULATION AND THROMBOSIS}

$\mathrm{T}$ WO main difficulties are immediately recognizable in research on blood coagulation. Only two or three of the dozen or so components of the blood-clotting system have been obtained in a state approaching purity, but the continued application of physico-chemical separations will probably improve this situation in the course of time. The second difficulty is the multiplicity of terms for components which can only be recognized by their effect on a clotting system, and thus it is very welcome news that an International Committee on the Nomen. clature of Blood Clotting Factors is being formed to resolve the existing confusion. The editor and panel of contributors to the recent issue of the British Medical Bulletin $(11$, No. $1 ; 1955)$ are therefore to be congratulated on maintrining the high standard of review associated with the journal in a field where there are exceptional difficulties.

In his introduction, R. G. Macfarlane points out that research in blood coagulation, which for more than a century has moved at a strictly academic tempo, has recently acquired a remarkable acceleration which he attributes partly to studies of hæmorrhagic states (defective coagulation) and partly to the intro. duction of anticoagulant therapy for thrombosis (excessive coagulation). Tests of clotting efficiency, discussed by Dr. Rosemary Biggs, contribute both to the diagnosis of hrmorrhagic states and to the control of anticoagulant therapy.

Recent advances in the understanding of hremophilia and allied disorders are presented by W. R. Pitney and J. V. Dacie. C. Hougie discusses another group of coagulation defects - those due to the development of anticoagulant factors in the blood. J. F. Ackroyd contributes two articles on the role of platelets in normal and pathological conditions, and J. B. Duguid discusses mural thrombosis in arteries.

Dr. Catherine Burt gives a very practical review of the clinical uses of anticoagulant drugs, discussing the heparin type of anticoagulant which acts directly on the blood-clotting system and also the coumarin type which acts by reducing the formation of bloodclotting factors. A table clearly sets out the doses, the times to obtain an effect and to return to normal afterwards, for the various coumarin-type drugs; the effect of the heparin type is obtained immediately after injection. Contra-indications and the results of therapy in various diseases are very thoroughly reviewed.

K. Bailey and F. R. Bettelheim discuss the conversion of soluble fibrinogen to insoluble fibrin by the enzyme thrombin. Here the picture of coagulation is clearer since fibrinogen and thrombin have recently been prepared in what appear to be pure forms. The discovery that the $\mathrm{N}$-terminal group of fibrin differed from that of fibrinogen led to the isolation of a peptide split off from fibrinogen by the action of thrombin during clot formation. These facts, first discovered with bovine fibrinogen, are being confirmed for human fibrinogen by current research. R. A. Kekwick describes the large-scale separation of some of the clotting factors from human plasma. These factors are generally required in a very pure state for diagnosis and research; but for clinical application moderate purity suffices.

A careful analysis of the mode of action of coumarin drugs is presented by A. S. Douglas, who concludes that the serum of patients under therapy with these drugs is defective in its ability to form thromboplastin. R. B. Hunter and D. M. Shepherd contribute an interesting article on the chemistry of coumarin anticoagulant drugs in which they point out that it is still not possible to define the minimum structural characteristics that are required to confer anticoagulant powers on the molecule. The relationship between anticoagulant activity and the opposing vitamin $\mathrm{K}$ activity is discussed, and it is pointed out that competitive inhibition between coumarin anticoagulants and vitamin $K$ exists only over a very limited dose-range. Vitamin $\mathbf{K}$ is a growth factor for certain micro-organisms, and a compound with antivitamin $K$ activity in this respect may or may not be an anticoagulant.

A very comprehensive review of the chemistry and mode of action of heparin and related compounds is provided by $\mathbf{K}$. W. Walton. After tracing the history of the purification of heparin through to present-day 
views on its structure, the relation between structure and activity is discussed. The most recently discovered feature of heparin structure, the sulphated amino-group, may or may not turn out to be the key to the remarkably high anticoagulant activity of heparin as compared with other sulphated polysaccharides. Regarding the mode of action of heparin on the clotting system, it seems probable that heparin intervenes at more than one point. It certainly functions as an antithrombin and probably acts also againgt thromboplastin.

In a fine concluding article entitled "The Rubicon : Changing Views on the Relationship of Thrombosis and Blood Coagulation", Prof. A. H. T. Robb-Smith entertains us with a glimpse of a review of coagulation and thrombosis as it would have been written a century ago, perhaps in the "British Medical Almanack" of 1855. He manages to include much that is illuminating to-day and inspiring for the future, and some very sobering thoughts on the necessity of studying coagulation in vivo and not only in artificial systems. It appears that, if we could predict the onset of thrombosis, we could, by careful use of the drugs available to-dsy, avoid the disease altogether-a worthy objective for the scientific approach in modicino.

C. R. Ricketrs

\section{UNIVERSITY OF LEEDS}

A $\mathrm{T}$ a meeting of the Court of the University of A Leeds on December 16, 1954, the vice-chancellor, Sir Charles Morris, said that if the universities of Great Britain have succeeded in assimilating new studies which are most exigent of both human and material resources without destroying the essential nature of academic communities, this is largely due to the sympathy and wisdom of successive governments, which have seen it as their first task to enable each university to preserve its own special academic character and balance of interests. Only when this is secured has the government sought to encourage developments in particular fields, such as studies in oriental languages, social studies and higher technological education. In regard to the last-named, the Government's most urgent concern is to increase the number of graduates in technology available for industry and commerce after taking their first degree. So far as the University of Leeds is coneerned, continued Sir Charles, the main limiting factor is accommodation; but some overcrowding has been accepted in the expectation that the necessary new buildings and extensions can be undertaken without great delay.

Sir Charles stated that it was expected to complete the chemistry and physics buildings of the University within the next few weeks, and a capital grant from the University Grants Committee will enable the work to begin without delay upon the first stage of the remaining extension; this extension is an essential part of the expansion of the technological departments, for which a new building has in addition been planned. Work on the first section of this latter building, to house the Department of Fuel Science, including now chemical engineering and metallurgy, was expected to start in about three months, with the aid of a large capital grant from the University Grants Committee. Accommodation available for the Medical School is also being increased, including new accommodation for the Departments of Biochemistry and of General Medicine; and in due course, as part of the City development plen for the area north of the General Infirmary, it is hoped to plan and build a new Medical School. It is hoped to start the building of the first section of the new arts block early in 1957. This building, on the south side of University Road, is to have an impressive frontage looking south and is to balance the science block on the north side of the Parkinson Building.

Referring to the Government's known view that leaders of the future in technology should be educated in the university manner, side by side with the scientific workers and medical workers and those destined for the older professions, Sir Charles asid that it is of the greatest importance that the universities should retain their traditional character and way of life. He thought that at Leeds, while not doing all that could be done, they were succeeding in this and were determined to do better still.

\section{ANATOMY AND ANGIOSPERM CLASSIFICATION}

TN an essay entitled "An Anatomist's Views on 1 Angiosperm Classification" (Kew Bull., No. 3, 427 ; 1954), C. R. Metcalfe has applied himself to the problem of how the taxonomist, confronted with the Angiosperms in all their abundance and diversity of species, can be helped in his aim to produce a natural classification, by making use of the results of laboratory investigations. Long experience has shown that the morphology of the reproductive structures, apparently less plastic than the other parts of the plant body, affords the most reliable criteria for purposes of classification. Nevertheless, the case is now forcefully presented that the micro-morphological characters of the vegetative organs can be used to advantage in taxonomic studies. Indeed, it has been shown that the conclusions based on the obser. vation of such characters may show a large measure of agreement with those reached by the traditional methods.

In the body of the article, the author discusses critically, with citation of many interesting examples, the parallelisms in the evolution of the woody elements, for example, tracheids to vessels, scelariform end-wall plates to simple perforations, etc., the relationship of herbs to ligneous plants, and the Durian theory. He notes that if the diagnostic microscopic characters for most taxonomic groups above the level of families are surveyed, it becomes evident that orders and taxa of higher rank are heterogeneous. From this he concludes that orders are probably, with some exceptions, taxonomio conveniences, rather than assemblages of genetically related plants. By contrast, a study of the diagnostio microscopic characters of genera in individual families supports the view that most families appear to be homogeneous and therefore constitute natural groups. Where exceptions occur, this generally indicates a need for some taxonomic revision, or that a large family needs to be divided into distinet groups. The author concludes that taxonomy is likely to develop to the best advantage by the collaboration of the herbarium botanist with those who approach the subject by laboratory techniques. Moreover, the laboratory approach to taxonomy should lead to a closer integration of systematic with other branches of botany. 